\title{
A Study Regarding the Elaboration of an Integrated Regional Cluster, as a Support for Agro-Industrial Business in the Romanian Rural Areas
}

\author{
Silviu Beciu ${ }^{1}$, Ana Ursu $^{2}$, Oana Popa ${ }^{1}$ and Stefania Nistor ${ }^{1}$ \\ ${ }^{1}$ University of Agricultural Sciences and Veterinary Medicine, Bucharest, Bvd. Marasti, Romania \\ ${ }^{2}$ Institute of Research and Development for Agrarian Economy, Bucharest, Bvd. Marasti, Romania
}

\begin{abstract}
The clusters with agro-industrial profile were developed within this scientific paper, based on a new conception of the capitalization of agricultural production at a regional level. In this approach "the agricultural farms" are more than basic links of the agro-industrial chain, they are the "essential links" without which "the chain" cannot serve as economic and social organization. The consumer has become the basic link of the chain, and in order to meet its requirements and options, the agro-industrial enterprises must come in a more effective way. The cluster proposed by this study must produce "what is required" and "how much is required" on the market. This agroindustrial chain highlights the cluster size (type, dimension and production capacity of goods), its chain links and the value added by this cluster. The overall objective of the "network enterprises" which constitute this agro-industrial cluster is to help its members to achieve increased production capacity and to be more profitable. A cluster model for enhancing grain production, integrated at regional level is proposed within this study.
\end{abstract}

Keywords: cluster, agro-industrial chain, regional level

\section{Introduction}

Economic clusters, and in particular identifying, encouraging and planning their development have become a topical issue in recent years. The concept of "cluster" has a pretty long history, assigning different names, including "pole of competitiveness", "industrial district" and "industrial cluster". The terms that are imposed in the present research are "cluster" and "pole of competitiveness" (in France and Belgium), but the most used term in Romania is "cluster" (Romanian Ministry of Economy Guide for implementation in Romania of the concept of innovative cluster, 2009). The simplest description of the clusters is based on the relationship of supplier-customer and value chain. Most enterprises buy "inputs" (materials, services, components) from other suppliers and incorporate them into their products that they sell to customers. Enterprises functioning in "agro-industrial" clusters bring them a competitive advantage as they have a dense network of suppliers and customers nearby. The "value chain" concept derives from Alfred Marshall theory (1890) which characterized clusters as a "concentration of specialized industries in particular localities". For example, in northern Italy there are small clusters consisting of companies that are specialized

Copyright (C) 2012 Silviu Beciu, Ana Ursu, Oana Popa and Stefania Nistor. This is an open access article distributed under the Creative Commons Attribution License unported 3.0, which permits unrestricted use, distribution, and reproduction in any medium, provided that original work is properly cited. Contact author: Silviu Beciu E-mail: beciu_silviu@yahoo.com 
properly in the various stages of production. Among these there are relations of coordination. Marshall has based his theory on observations made on the situation of "industrial districts" in England, according to which companies located in the same geographical area are more effective than if they work long distance. He explained that development of industrial complexes determined by the existence of positive externalities within agglomerations of interrelated enterprises and industries is caused by three major forces: knowledge exchanges between enterprises, specialized inputs and services from supporting industries, and a localized labour market for specialized skills.

Michael Porter (1990) introduced the term of business cluster, also known as an industry cluster, competitive cluster, or later as Porterian cluster. He said that clusters suggest that a good deal of competitive advantage lies outside companies and even outside their industries, residing instead in the locations at which their business units are based. Michael Peneder (1997) affirmed that building upon the property of interdependent but organizationally independent decision making units, industrial clusters can be understood as "organic" economic systems, where the principles of evolutionary complexity apply.

Recent national researches demonstrate that the agribusiness is the largest need-based organization of clusters, because rural development is a major strategic objective of the European Union and in Romania it can not be achieved while maintaining the current forms of economic cooperation and social organization. Agro-industrial production systems have strong regional characteristics plains, hills and mountains) that can be mastered better by cluster organizations. The phenomena of economic integration, both horizontally and vertically, can be identified in the Romanian agriculture and these can be enhanced organizing agroindustrial types of clusters at regional level.
Romania's accession period to European Union noted in 1998 the creation of eight regional development regions which are named after their geographical position in the country: The South Muntenia Region, The Bucharest-Ilfov Region, The North-East Moldova, The South-East Region, The NorthWest, The South-West Oltenia Region, The West Banat Region and The Centre Region. Even if Romania's development regions don't actually have an administrative status, they play a vital role in absorbing funds from the European Union, which is coordinating regional development projects. Although irregular in terms of area or existing population, all regions have a common feature of regional development in terms of socio-economic: there are large disparities between rural and urban areas, which require solutions to achieve a balance between these two areas to prevent long term adverse effects on rural areas. In almost all these regions, agriculture is one of the main productive sectors nationwide. There are also clear regional differences, and therefore must be pursued to achieve a balance between economic and social development levels of different areas.

In this regional context, the development of agro-industrial clusters in the rural areas can be a viable solution, if we consider that development of strictly agricultural cluster might be harder and more expensive than combining agricultural with agro-industrial enterprises, the last of them having better possibilities in capitalization of their outputs. Clusters are in fact new forms of organizational networks operating on the theory of firms. The enterprises network with agro-industrial profile is a new concept emerged, and known in the last decade of the second millennium.

\section{Material and Methods}

The study methodology and techniques used in developing the experimental and functional model were based on: methods of investigation by documenting the area 
mentioned and processing of normativeconstructive methods. The experimental model was simulated as several variants of cluster and organizational structures were identified as possible cluster organized / developed at regional level in rural areas. The experimental models taken into account for designing the new model, which has similarities but also differences from the other types of associations were: The Local Actions Groups, The Marketing Associations in Agriculture, The Agricultural Cooperatives, The Scientific and Technological Parks and Clusters - as contract-based groups of firms and Clusters as support framework for the internalization of enterprise activities. The new form of agro-industrial cluster which was based on selecting and combining the biggest advantages of these forms of associations: is an agreement freely consented among several entities to achieve a common goal; the entities in the cluster retain their legal personality and are limited to a lesser or greater decisional independence; the new model of cluster is not therefore a new business, but an association of undertakings for a period of time which is considering achieving joint dominance in that market; the new model of agro-industrial cluster can be achieved into two types: simple, involving only improving the agreement among the parties by which they limit their economic independence in certain activities, or complex, which requires additional and improved establishment of common functional compartments. An applied form of cluster was created within the project No.92-111/2008 financed by Romanian -UEFISCDI, "Research on The Development of Romanian Agribusiness Clusters". The model introduced is helpful since it can be applied in any Romanian region of development.

The first applied cluster model meant a private-public partnership agreement between the founding partners (two Regional Development Agencies, one County Council, two Agricultural Producers Associations and one State University) and the economic agents within the food chain from a region of development (farmers, storage, millers, processors, traders). The selection of the founding partners was made starting from their specific role: The Regional Development Agencies are coordinators of policy-making in sustainable regional development; the County Council develops and implements policies and coordinates efforts of local sustainable development and economic resources of the cereal in the county; The Agricultural Producers Associations are involved in application of advanced technologies and raising grain, raw materials, quality and economic competitiveness; The State University is a provider of research and innovation in management, innovative technology and equipment provider, consultancy and implementation of innovative technologies. The motivation of the partners within the selected food-chain and the need for collaboration among them are related to the idea of fair distribution of profit.

Other object of the research was to identify the regions in which such associations forms can bring maximum benefits for a certain type of production. For example The South East Region was found suitable for agroindustrial clusters with cereal production profile, unlike The North East Region which was found suitable for vegetable production. The study provides experimental model solutions and functional model cluster for the cereals production and capitalization, new and complex structures from which they expect positive results in economic, social and rural development.

\section{Results and Discussions}

The value chain analysis system is based on the assumption that the chain itself may be designed as a "group" or "network" of enterprises gathered for the production, storage, processing and marketing of cereals. If we accept this perspective, we also admit the hypothesis that in this agro-industrial chain, as well as in the group of enterprises it is possible to produce a "consolidated financial statement." In summary, analysis of 
the common value of this agro-industrial cluster with cereal production and industrialization profile is based on creating a chain of consolidated financial statements.

The economic chain, from the point of view of the cluster concept, founded and promoted in this study, is based on a new conception regarding cereals production. In this view "agricultural farm" is not the basic link of the chain, but "essential link" without which "agro-industrial chain" can not serve as economic and social organization. The basic link in our view is "the consumer" and in order to meet its requirements and options, the commercial enterprises must come in a more effective way. The cluster proposed by this study must produce "what is required" and "how much is required"

The agro-industrial cluster proposed by this study, named AGRO-INDRUSTRIAL CEREAL CLUSTER contains 5 rings (V1-V5):
V1- up of trading enterprises (the bread, bakery products and pastries) that are always in relationship with the consumer knows the request and asks for links so as to make products requested;

V2 - bread factories carrying trade goods required;

V3 - milling enterprises receiving orders from flour mills and bakery bread;

V4 - storage units / storage of grain for the requirements of manufacturers of bread and other grain consumption for the production of concentrated feed, alcohol, export and other uses;

V5 - Farms / grain producing farms that produce for sale and for consumption.

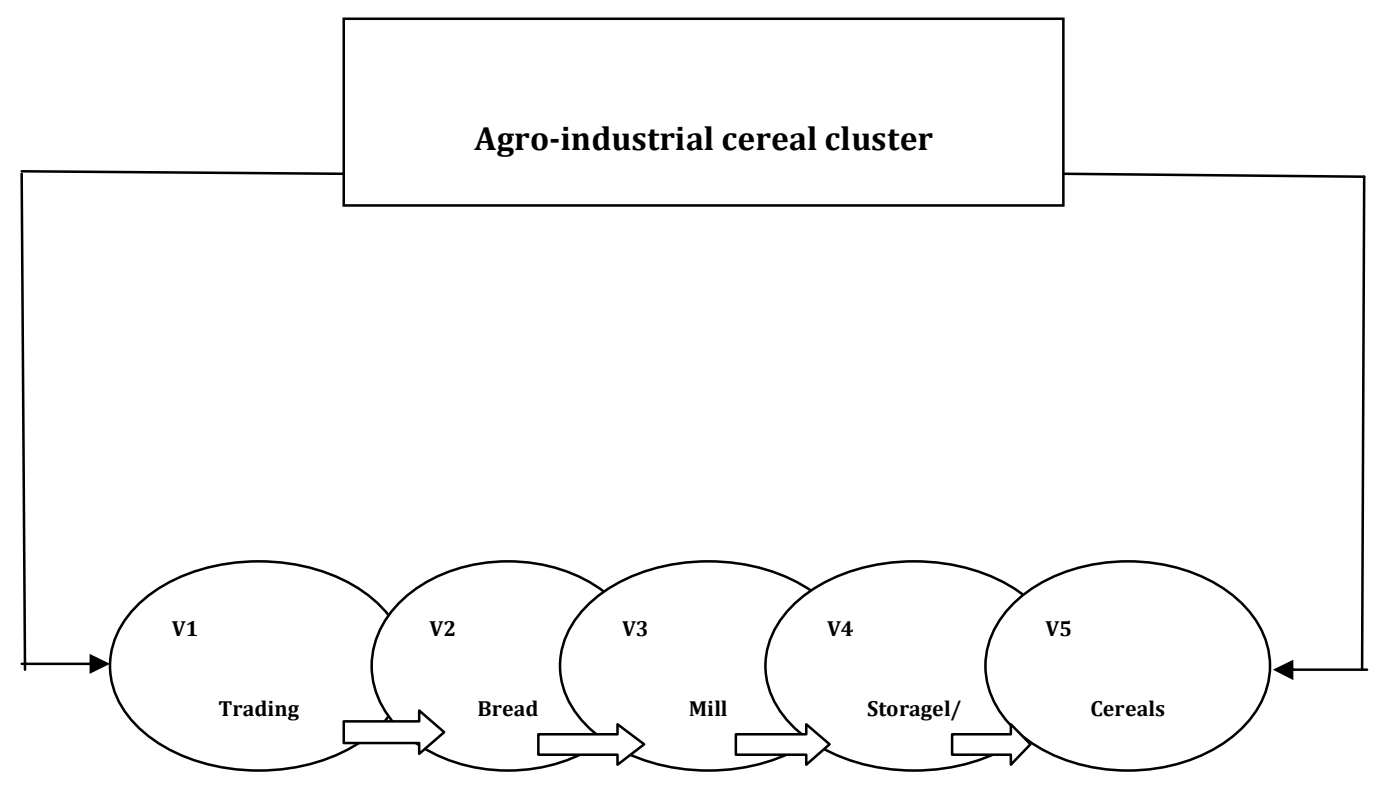

Fig. no. 1: Agro-industrial cereal cluster - Scheme of analyzing the value added chain links - Author: Ana Ursu, scientific researcher within Romanian Institute of Research and Development for Agrarian 
The overall objective of the cluster is to increase quantity, quality and value of regional cereal production, increase farmers' income and grain production efficiency in Romania, as part of the national economy. It will be adding value to the "cereal agroindustrial chain". To prove this statement still present an outline of the main indicators of cluster analysis and principal value added to the total and for each link.

Table1. The Costs, Income and Added Value of the AGRO-INDRUSTRIAL CEREAL CLUSTER

\begin{tabular}{|c|c|c|c|c|c|c|}
\hline & V1 & V2 & V3 & V4 & V5 & Total (lei) \\
\hline Total costs & 150.000 & 100.000 & 85.000 & 75.000 & 50.000 & 460.000 \\
\hline $\begin{array}{c}\text { Income } \\
\text { earned by } \\
\text { selling } \\
\text { production }\end{array}$ & 195.000 & 150.000 & 100.000 & 85000 & 75000 & 605.000 \\
\hline $\begin{array}{c}\text { Added } \\
\text { value }\end{array}$ & 45.000 & 50.000 & 15.000 & 10.000 & 25.000 & 145.000 \\
\hline
\end{tabular}

Source: Calculations made by Romanian Institute of Research and Development for Agrarian Economy, 2010, 1 euro = 4.1 lei, 2010

It can be seen that in this chain of production of bread, that starting with an agricultural input of $50.000 \mathrm{RON}$, the total added value is 145.000 RON, thus obtaining an output of 195.000 RON. The amount of 50.000 RON input can be achieved by a 20-hectare farm that produces about 100 tones of wheat, corn and barley in cereal equivalent. $5 \mathrm{t} / \mathrm{ha} \mathrm{x} 20$ ha $=100$ to $/$ farm; 100 to $\times 500$ lei $/$ to = 50.000 lei / farm.

\section{Sizing Agro-industrial Cluster for Cereals}

The agro-industrial cluster model for cereal that was designed can be characterized by size, dimension, and commodity production. In the current design, the three notions are as follows:

- Cluster size is its production capacity, due to the volume of existing production resources in the area which is organized and the degree of their use in the production process. Cluster dimension is significantly different from that of size, the difference consisting in that size refers to the concentration of production, while the dimension is related to the land available for the cluster.

- Unlike dimension, which expresses the quantitative aspect of the process of concentration, size is the qualitative side, and it includes both the means of production of equipment and production intensity degree. In the literature, agricultural land is becoming less used as a criterion of dimension.

- Commodity production will replace the cluster physical dimension by economic dimension, which is given mainly by the total commodity output produced. It also may use gross profit as a criterion of cluster.

We consider that within the cluster there must be added a new feature, namely socioeconomic dimension, targeting both economic component and a social one. Optimal, economic and social dimensions of a cluster structure must fully satisfy a wide 
range of economic and social criteria such as: rational crop production and highest profit per hectare (for V5), the appearance of accumulated capital investment opportunities (for all agro-industrial cluster links); energy independent criteria (applied on chain where possible in terms of efficiency).

After evaluating the demand of the grain market and competitors in this market, management structure of the cluster, develop medium-term development plan and annual plan of action long. In these plans will be found: The overall objectives of the cluster, each link component objectives, ways of achieving them, scientifically based decision adopted by the governing bodies, actions / activities to achieve objectives and appropriate allocation of resources, powers, responsibilities and powers of people, cluster departments and bodies, reporting / monitoring and analysis of results.

\section{Conclusions}

The purpose of the economic chain experimental model proposed in this study is to identify changes in cereals agro-industrial chain in terms of how the market works and find ways to make it more competitive and to gain advantages in competition. The results show that the value is usually created by processing and distribution stages, to the detriment of the primary sector, and retail practices tend to require structural changes in the farms, whose profitability seems to be sustainable only because of The European Union subsidies. To conclude, it is obviously an inadequate definition of network and strategic alliance across the actual agricultural chain. Competitiveness is still only a concept developed by the stages of the food chain in comparison with others, and internal competition in the food chain involves sustainability of small farms and agro-industrial enterprises. The agroindustrial and food chain perspectives should strengthen their strategic alliance and network along the chain, being aware of the fact that external competition, competitiveness and sustainability require a stronger coalition and partnership in the chain. The proposed cluster model has positive results in: a better identification of needs, priorities and outlook of member's partners, including research, development and regional innovation, competitiveness, business support in the region and creating a structure with international visibility; increasing synergies between partners by providing highly professional services for Small and Medium Sized Enterprises, including attracting funding for innovative projects, simplifying administrative procedures; increasing institutional cooperation for a better absorption capacity of EU funds, improving and streamlining planning and scheduling the use of funds; transferring of know-how and exchange of best practices.

\section{Acknowledgment}

The results are part of the Project "Research On Actual Size Evaluation And The Perspective Of Sustainable Rural Development Through The Elaboration of SWOT Analysis, As Method of Strategic Planning For The North-East Region of Romania", under a financial scheme supported by Romanian National Council for Scientific Research in Higher Education: CNCSIS-UEFISCSU (Grant no 114/28.07.2010), Project manager: Silviu BECIU. Ana URSU contributed to this article with the results of the project PN II Partnership No.92-111/2008: "Research on The Development of Romanian Agribusiness Clusters", financed by UEFISCDI.

\section{References}

Beckeman, M. \& Skjöldebrand, C. (2007). "Clusters/Networks Promote Food Innovation," Journal of Food Engineering, 79: 1418-1425.

Bertazzoli, A., Ghelfi, R., Rivaroli, S. \& Samoggia, A. (2010). "Value Sharing and Food System Dynamics for Milk, Tomato, and 
Cereals Food Chains," The International Journal on Food System Dynamics, vol. 1 (4)

Constantin, M. (2007). Marketing of Agroindustrial Production, Ed.AgroTehnica, Bucharest

Guidelines for Implementation of the Concept of Cluster Innovative Romania (2009). Romanian Ministry of Economy Bucharest

Ketels, C. (2004). European Clusters Structural Change in Europe. Innovative City and Business Regions. Hagbarth Publications, Bollschweil

Marshall, A. (1890). Principles of Economics, MacMillan, London

Maskell, P. (2001)."Towards a Knowledgebased Theory of the Geographical Cluster," Industrial and Corporate Change; 10: 921943
Peneder, M. (1997). "Creating a Coherent Design for Cluster Analysis and Related Policies. The Austrian "tip" Experience, "OECD, Amsterdam

Porter, M. (1990). 'The Competitive Advantage of Nations,' Harvard Business School - Location, Competition, and Economic Development: Local Clusters in a Global Economy

Rosenfield, S. A. (1997). "Bringing Business Clusters into the Mainstream of Economic Development," European Planning Studies, Vol. 5-1:3-23

Shucksmith, M., Thompson K. J. \& Roberts D. (2005).' The CAP and the Regions - The Territorial Impact of the Common Agricultural Policy,' CABI publishing, Wallingford, UK; ISBN 0-85199-055-X

Turek, A. (2007). Competiveness of Cereals Chain, Ed. University Book Bucharest 